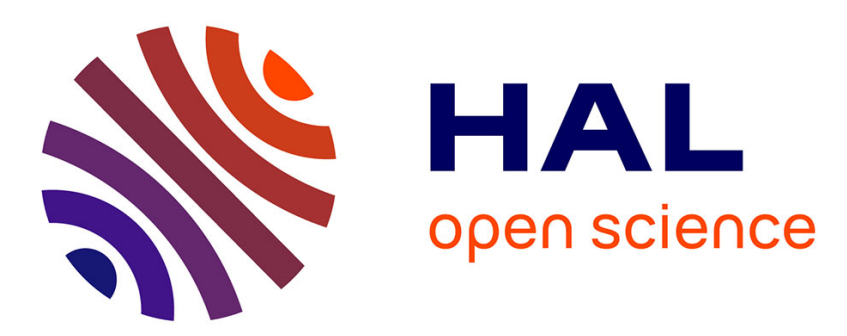

\title{
Temperature Dependent Re L3-Edge X-Ray Absorption Study of Crystalline Rhenium Trioxide ReO3
}

\author{
A. Kuzmin, J. Purans, G. Dalba, P. Fornasini, F. Rocca
}

\section{To cite this version:}

A. Kuzmin, J. Purans, G. Dalba, P. Fornasini, F. Rocca. Temperature Dependent Re L3-Edge X-Ray Absorption Study of Crystalline Rhenium Trioxide ReO3. Journal de Physique IV Proceedings, 1997, 7 (C2), pp.C2-1119-C2-1120. 10.1051/jp4:19972152 . jpa-00255215

\section{HAL Id: jpa-00255215 https://hal.science/jpa-00255215}

Submitted on 1 Jan 1997

HAL is a multi-disciplinary open access archive for the deposit and dissemination of scientific research documents, whether they are published or not. The documents may come from teaching and research institutions in France or abroad, or from public or private research centers.
L'archive ouverte pluridisciplinaire HAL, est destinée au dépôt et à la diffusion de documents scientifiques de niveau recherche, publiés ou non, émanant des établissements d'enseignement et de recherche français ou étrangers, des laboratoires publics ou privés. 


\title{
Temperature Dependent Re $\mathbf{L}_{\mathbf{3}}$-Edge X-Ray Absorption Study of Crystalline Rhenium Trioxide $\mathrm{ReO}_{3}$
}

\author{
A. Kuzmin, J. Purans, G. Dalba*, P. Fornasini* and F. Rocca** \\ Institute of Solid State Physics, 8 Kengaraga str., 1063 Riga, Latvia \\ * INFM, Università di Trento, 38050 Povo (Trento), Italy \\ ** Centro CNR-ITC di Fisica degli Stati Aggregati ed Impianto Ionico, 38050 Povo (Trento), Italy
}

\begin{abstract}
X-ray absorption spectroscopy study of crystalline $\mathrm{ReO}_{3}$ was performed at the $\mathrm{Re}_{2}$-edge in the temperature interval from 77 to $670 \mathrm{~K}$. The analysis of both XANES and EXAFS regions shows that in $\mathrm{ReO}_{3}$, a progressive localization of the $5 d$ states following the temperature increase is accompanied at $T>350 \mathrm{~K}$ by a distortion of the $\mathrm{ReO}_{6}$ octahedra. The distortion increases continuously up to the $\mathrm{ReO}_{3}$ decomposition temperature $T_{\mathrm{d}} \approx 673 \mathrm{~K}$ and leads to the lowering of the rhenium site symmetry from $O_{\mathrm{h}}(T \leq 350 \mathrm{~K}) \rightarrow D_{4 \mathrm{~h}}(T \approx 513 \mathrm{~K}) \rightarrow C_{4 \mathrm{v}}(T \approx 668 \mathrm{~K})$. The observed distortion is explained by (i) the strong electron-phonon coupling of the $5 d$ electron with the $M_{3}$ and $M_{3}^{\prime z}$ phonons and (ii) the Jahn-Teller-like effect caused by the rhenium $5 d^{1}$ electron which becomes localized at high temperature.
\end{abstract}

$X$-ray absorption spectroscopy study of polycrystalline rhenium trioxide $\operatorname{ReO}_{3}$ has been performed on the $\mathrm{Re} \mathrm{L}_{3}$-edge in the temperature range from $77 \mathrm{~K}$ up to the $\mathrm{ReO}_{3}$ decomposition point $T_{\mathrm{d}} \approx 673 \mathrm{~K}$. The $\mathrm{x}$-ray absorption spectra were measured in transmission mode at the ADONE (Frascati) and DCI (Orsay) storage rings, and the experimental detailes can be found in [1]. $\mathrm{ReO}_{3}$ has a perovskite-type cubic structure composed of regular $\mathrm{ReO}_{6}$ octahedra joined by vertices. Rhenium ions $\mathrm{Re}^{6+}$ in $\mathrm{ReO}_{3}$ have $5 d^{\mathrm{L}}$ electronic configuration resulting in the partially filled $5 d$-band and metallic conductivity [2]. The presence of $5 d$-electron is responsible for the stability of the $\mathrm{ReO}_{3}$ lattice and the absence of any structural phase transitions at atmospheric pressure that is opposite to many other perovskites $\left(\mathrm{BaTiO}_{3}, \mathrm{SrTiO}_{3}\right.$ etc) and perovskite-like compounds $\left(\mathrm{WO}_{3}\right)$.

The XANES analysis shows that a strong modification of the local electronic structure occurs with increasing temperature. It can be explained (1) by a progressive narrowing of the $t_{2 g}$ and $e_{g}$ sub-bands with a localization of the electron states (especially having $e_{g}$ character) at rhenium sites due to the electron-phonon coupling (Figure $1(a)$ ) and (2) by an increase at $T>470 \mathrm{~K}$ of the effective charge on rhenium ions leading to a shift in the position of the absorption edge and the white line (WL) maximum (Figure 1(b)).

The analysis of EXAFS suggests that a distortion of the $\mathrm{ReO}_{6}$ octahedra occurs at $T \approx 380 \mathrm{~K}$ while the sub-lattice formed by $\mathrm{Re}$ atoms remains regular. This conclusion is supported by the dependence of the average mean square relative displacements (MSRD) $\sigma^{2}\left(=\sigma_{\mathrm{th}}{ }^{2}+\sigma_{\mathrm{st}}{ }^{2}\right)$ on the temperature (Figure 2). The deviation of the MSRD $\sigma^{2}\left(\operatorname{Re}-\mathrm{O}_{1}\right)$ in the 1 st shell from the Debye model behaviour means that for $T>350 \mathrm{~K}$, both thermal $\sigma_{\mathrm{th}}{ }^{2}$ and static $\sigma_{\mathrm{st}}{ }^{2}$ disorder are present (Figure 2(a)). At the same time, the MSRD $\sigma^{2}\left(\operatorname{Re}_{-} \mathrm{Re}_{4}\right)$ in the 4th shell follows the Debye law (Figure 2(b)) so that the static distortion of the rhenium sub-lattice is expected only near the decomposition temperature $T_{d}$ (see the last point in Figure $2(\mathrm{~b}$ )). The results of the MSRD anaiysis agree well with the radial distribution functions (RDF) obtained for the 1st shell of rhenium (Figure 3(a)). Thus, we suggest the following model for the modifications occuring within the $\mathrm{ReO}_{3}$ structure upon heating. The electronphonon coupling, caused by the $M_{3}$ phonon mode, leads already at low-temperatures to the progressive localization of the $5 d$ states at rhenium sites. This process results at $T>350 \mathrm{~K}$ in the localization of the $5 d^{3}$ electron and the Jahn-Teller-like distotion (Figure 3(a)) leading to the lowering of the local symmetry at rhenium sites from $O_{\mathrm{h}}$ to $D_{4 \mathrm{~h}}$. On temperature increase, at $T \approx 563 \mathrm{~K}$, the further distortion of the $\mathrm{ReO}_{6}$ octahedra from $D_{4 \mathrm{~h}}$ to $C_{4 v}$ local symmetry appears which can be explained by the coupling of the $5 d$ electron with the $M_{3}^{\prime 2}$ phonons.

The obtained results suggest that the stability of the $\mathrm{ReO}_{3}$ lattice, caused by the presence of the $5 d^{1}$-electron, can be broken by temperature increase and, thus, the temperature dependence of the $\mathrm{ReO}_{3}$ conductivity at high temperatures. $(500<\mathrm{T}$ $<670 \mathrm{~K}$ ) could deviate from its low-temperature behaviour.

\section{Acknowledgments}

The authors are grateful to the staff of the ADONE PWA laboratory and of the LURE DCI EXAFS-3 beamline for the support of the experiments. A.K. and J.P. wish to thank partial support of this work from the Centro CNR-ITC (Trento) and the Università di Trento. This work was also supported in part by the NATO Guest Fellowship No. 218.1596 (A.K.) and the International Science Foundation, Grants LF8000 and LJ8100 (A.K. and J.P.). 

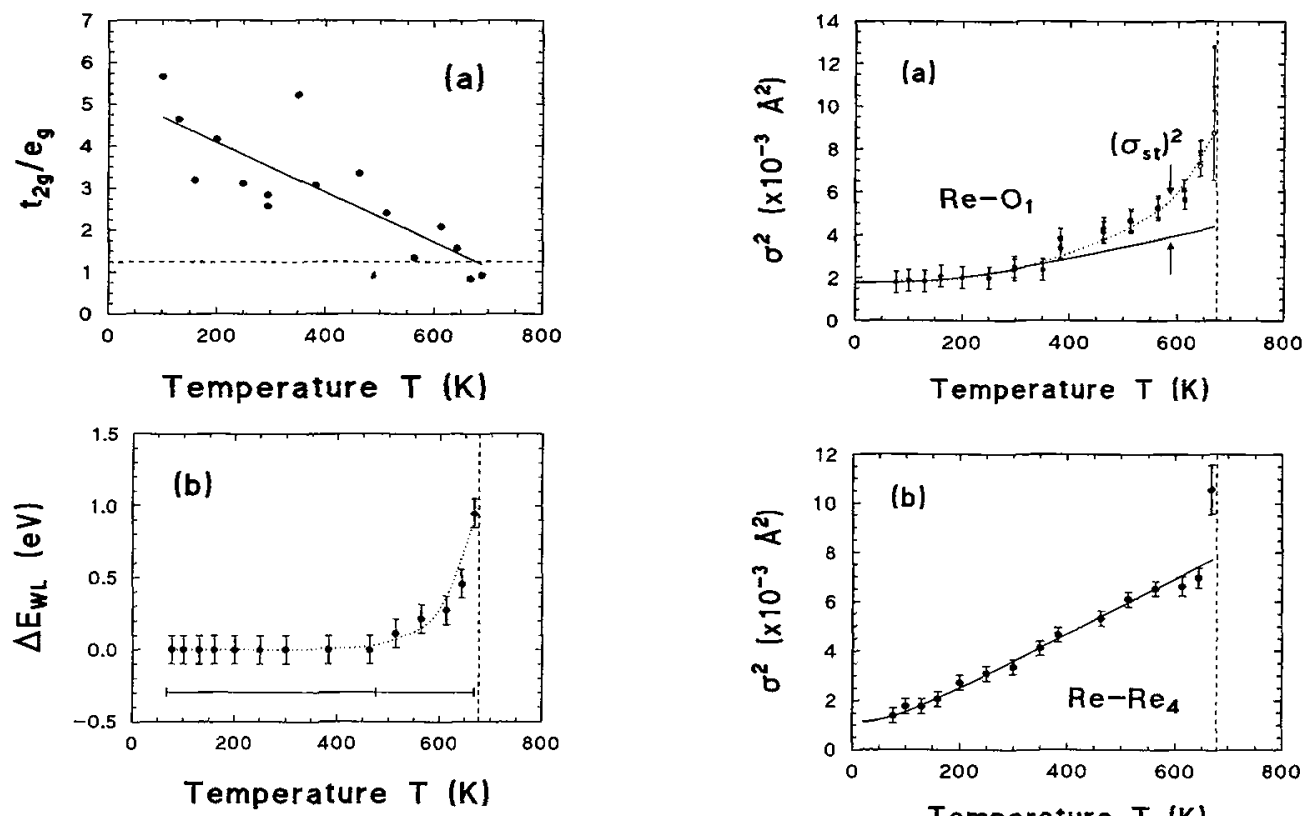

Figure 1: (a) Temperature dependence of the ratio $t_{2 g} / e_{g}$ :

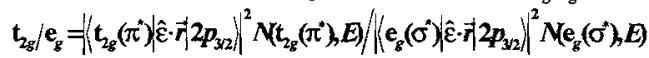
which shows the variation of the number of the free states and the localization degree for two sub-bands. The dashed line corresponds to the fully localized orbitals with the number of unoccupied states equal to five in $t_{2 \mathrm{~g}}$ and four in $\mathrm{e}_{\mathrm{g}}$ sub-bands. (b) Temperature dependence of the WL maximum shift $\Delta \mathrm{E}$. Dotted line is a guide for eye. Vertical dashed line shows the $\mathrm{ReO}_{3}$ decomposition temperature $T_{\mathrm{d}} \approx 673 \mathrm{~K}$.
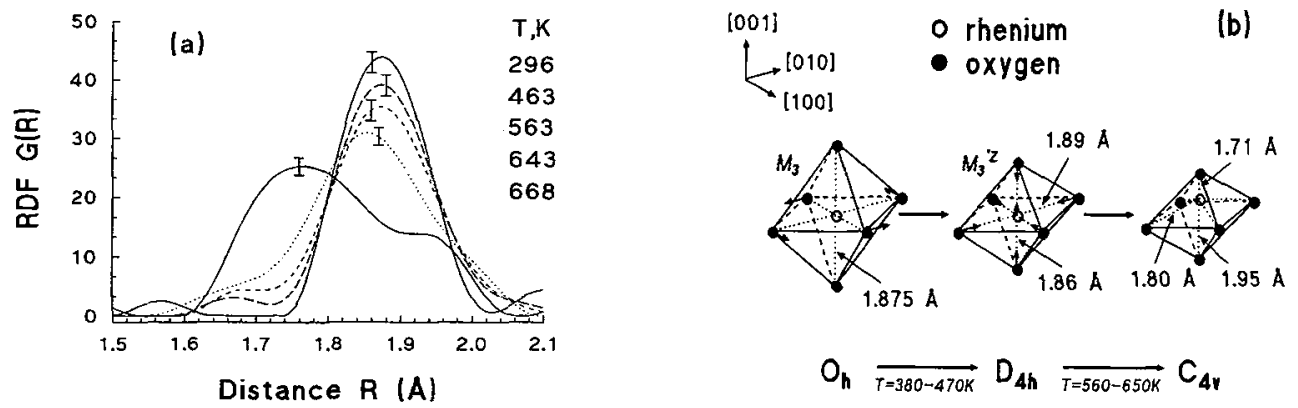

Figure 3: (a) $\operatorname{RDF} G(R)$ for the first shell of rhenium in $\mathrm{ReO}_{3}$ at various temperatures. An asymmetry of the $\mathrm{RDF} G(R)$, consisting of the tail at the left side of the peak (at $R \sim 1.7 \AA$ ), progressively increases with temperature passing to the double-peak shape at $T=668 \mathrm{~K}$. (b) $\mathrm{A}$ model of the high-temperature behaviour of $\mathrm{ReO}_{3}$ within the first coordination shell: the local symmetry at the rhenium site decreases successively from $O_{\mathrm{h}}$ to $D_{4 \mathrm{~h}}$ and $C_{4 \mathrm{v}}$. The rhenium atom is shown by open circle and the oxygen atoms by solid circles. The displacements, caused by the $M_{3}$ and $M_{3}^{\prime 2}$ phonon modes, of oxygen atoms leading to the distortion of the 1st shell are shown by arrows.

\section{References}

[1] Dalba G., Fornasini P., Kuzmin A., Purans J. and Rocca F., J. Phys.: Condens. Matter 7 (1995) 1199-1213; J. Phys.: Condens. Matter (1996) (to be published).

[2] Pearsall T.P. and Lee C.A., Phys. Rev. B 10 (1974) 2190; King C.N., Kirsch H.C. and Geballe T.H., Solid State Commun. 9 (1971) 907; Tanaka T., Akahane T., Bannai E., Kawai S., Tsuda N. and Ishizawa Y., J. Phys. C: Solid State Phys. 9 (1976) 1235. 